\title{
A Broadband Rectangular Microstrip Patch Antenna for Wireless Communications
}

\author{
Settapong Malisuwan, Jesada Sivaraks, Noppadol Tiamnara, and Nattakit Suriyakrai
}

\begin{abstract}
In this paper, a simple design of wideband rectangular patch antenna is presented by using asymmetrical feed and a reduction in ground plane with proper gap distance. The frequency-dependent characteristic impedance included in the proposed procedure is addressed to eliminate possible errors in the high-frequency broadband applications. The antenna proposed in this research provides $2.3 \mathrm{GHz}$ bandwidth (frequency range: $0.9 \mathrm{GHz}-3.2 \mathrm{GHz}$ ) which can be utilized in various broadband applications such as remote sensing, biomedical and mobile radio. The proposed procedure in this research is compatible with $\mathrm{CAD}$ applications and is valuable contribution as it permits quick and easy design for RF engineers.
\end{abstract}

Index Terms-Microstrip, broadband, frequency-dependent, CAD.

\section{INTRODUCTION}

In mobile communication antenna design, the antenna has become an integral part of the mobile devices. To achieve this goal, the antenna for mobile sets must be small, flexible, and efficient. Rectangular microstrip patch antenna is one of the most utilized antennas because of its low cost, low profile and omnidirectional radiation pattern. A narrow bandwidth and low gain are main drawback of this antenna [1]. Higher bandwidth is desired in various applications such as remote sensing, biomedical, mobile radio, satellite communications etc. In order to improve the bandwidth, intensive research has been carried out and several techniques are proposed.

"The conventional methods for broadening impendence bandwidth are the following: modified shapes of the radiation element, partial ground plane feeding structure, inserting capacitor between the patch and the ground plane, inserting chip resistor between the patch and the ground plane, inserting a chip inductor " [1].

However, most of these antenna designs are either too complex or impractical for practical applications in $\mathrm{GHz}$ frequency range. The difficulty in designing a simple and compact antenna with broadband or multiband functions is still a challenge for engineers since the complexity and size of the antenna's structure is reduced and the operating frequency bands increase. As mentioned earlier, there is extensive literature that presented the design of broadband

Manuscript received March 5, 2014; revised May 14, 2014. Financial support for this research paper is provided by National Broadcasting and Telecommunications Commission, Bangkok, Thailand.

S. Malisuwan, J. Sivaraks, and Noppadol Tiamnara are with Vice Chairman of National Broadcasting and Telecommunications Commission Bangkok, Thailand (e-mail: settapong.m@nbtc.go.th, jesada.s@nbtc.go.th, noppadol.m@nbtc.go.th)

Y. Thamachareon is with the Royal Thai Armed Forces (e-mail: Y. thamachareon @gmail.com) rectangular microstrip antennas. However, previous studies have not included the effect of very high operating frequency in the procedure which increases chances calculation error in the model.

This paper presents a low cost and easy to fabricate microstrip patch antenna [2]. Moreover, in this research, the frequency-dependent characteristic impedance included in the algorithm is addressed to eliminate possible errors in the high frequency [3].

\section{Microstrip ANTENNA DESIGN}

Microstrip antenna consists of dielectric substrate located between the radiation patch on top and ground plane on other side as illustrated in Fig. 1.

The patch is made using conducting materials like copper and gold and can be made into any shape. However, the radiating patch and feed line is etched on dielectric substrate [4].

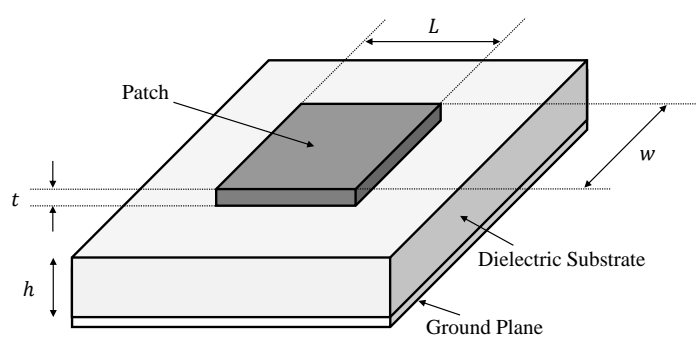

Fig. 1. Structure of a microstrip patch antenna.

For simplicity of analysis, the patch is generally square, rectangular, circular, triangular, and elliptical or some other common shape. For a rectangular patch, the length $L$ of the patch is usually in the range of $0.3333 \lambda_{0}<L<0.5 \lambda_{0}$, where $\lambda_{0}$ is the free space wavelength. The patch is selected to be very thin such that $t \ll \lambda_{0}$ (where $t$ is the patch thickness). The height $h$ of the substrate is usually $0.003 \lambda_{0} \leq h \leq 0.05 \lambda_{0}$. The dielectric constant of the substrate $\epsilon_{r}$ is typically in the range $2.2 \leq \epsilon_{r} \leq 12$ [3].

"For an efficient radiation a practical width of the rectangular patch element is" [5]

$$
w=\frac{1}{2 f_{r} \sqrt{\mu_{0} \varepsilon_{0}}}
$$

And the length of the antenna becomes

$$
L=\frac{1}{2 f_{r} \sqrt{\varepsilon_{e f f}} \sqrt{\varepsilon_{0} \mu_{0}}}-2 \Delta L
$$

where,

$$
\Delta L=0.41 h \frac{\varepsilon_{e f f}+0.3}{\varepsilon_{e f f}-0.258} \frac{\left(\frac{w}{h}+0.264\right)}{\left(\frac{w}{h}+0.8\right)}
$$


And [15]

$$
\varepsilon_{e f f}=\frac{\varepsilon_{r}+1}{2}+\frac{\varepsilon_{r}-1}{2}\left(1+10 \frac{h}{w}\right)^{-B}
$$

where $B$ is given by:

$$
\begin{aligned}
B=0.564\left\{1+\frac{1}{49}\right. & \ln \left(\frac{(w / h)^{4}+(w / 52 h)^{2}}{(w / h)^{4}+.432}\right) \\
& \left.+\frac{1}{18.7} \ln \left[1+\left(\frac{w}{18.1 h}\right)^{3}\right]\right\}\left(\frac{\varepsilon_{r}-0.9}{\varepsilon_{r}+3}\right)^{0.053}
\end{aligned}
$$

where, " $\lambda$ is the wave length, $f_{r}$ (in $\mathrm{Hz}$ ) is the resonant frequency, $L$ and $W$ are the length and width of the patch element, in $\mathrm{cm}$, respectively and $\varepsilon_{r}$ is the relative dielectric constant"[5].

To include the effect of high frequency in the procedure, the concept of microstrip-based Cole-Cole diagram is adopted to create frequency-dependent (lossy) characteristic impedance.

Prior to analyzing the frequency-dependent variables, the capacitance parameter in microstrip-line system should be analyzed. The capacitance per unit length of the classical parallel-plate capacitor is [6]:

$$
C=\varepsilon \frac{w}{h}
$$

"A simple frequency-dependent capacitance of the parallel-plate capacitor can be expressed in any frequency-dependent attributes of $\varepsilon$ which is" [5]

$$
C(\omega)=\varepsilon_{0} \varepsilon^{*}(\omega) \frac{w}{h}
$$

where $\varepsilon^{*}(\omega)$ is a complex permittivity is expressed as $\varepsilon^{\prime}(\omega)-j \varepsilon^{\prime \prime}(\omega)$. Therefore,

$$
C(\omega)=\varepsilon_{0} \varepsilon^{\prime}(\omega) \frac{w}{h}-j \varepsilon_{0} \varepsilon^{\prime \prime}(\omega) \frac{w}{h}
$$

Referring to the equivalent Cole-Cole diagram deduced for a parallel-plate microstrip line in [7] is substitute into Eqn. (8). Hence,

$$
\begin{aligned}
C(\omega)=C\left(\frac{1}{1+Q(\omega)}\left[Q(\omega)+\frac{\varepsilon_{e f f}}{\varepsilon_{r}}\right]\right) \\
-j \frac{C}{\varepsilon_{r}}\left[\varepsilon_{u}^{\prime \prime}(\omega)+\varepsilon_{c}^{\prime \prime}(\omega)+\varepsilon_{d}^{\prime \prime}(\omega)\right]
\end{aligned}
$$

where $C=\varepsilon_{0} \varepsilon_{r}(w / h)$.

For simplicity, the coefficients of Eqn. (9) are defined as follows:

$$
\begin{gathered}
A(\omega)=\frac{1}{1+Q(\omega)}\left[Q(\omega)+\frac{\varepsilon_{e f f}}{\varepsilon_{r}}\right] \\
B(\omega)=\frac{1}{\varepsilon_{r}}\left[\varepsilon_{u}^{\prime \prime}(\omega)+\varepsilon_{c}^{\prime \prime}(\omega)+\varepsilon_{d}^{\prime \prime}(\omega)\right]
\end{gathered}
$$

In general, the characteristic impedance of a transmission line is given by

$$
Z_{0}=\sqrt{\frac{R+j \omega L}{G+j \omega C}}
$$

where $R, L, G, C$ are per unit length quantities defined as follows:

$R=$ resistance per unit length in $\Omega / \mathrm{m}$.

$L=$ inductance per unit length in $H / \mathrm{m}$.

$G=$ conductance per unit length in $S / \mathrm{m}$.

$C=$ capacitance per unit length in $F / \mathrm{m}$. [8]

If $G$ and $C$ are neglected, the characteristic impedance can be written as:

$$
Z_{0}=\sqrt{\frac{L}{C}}
$$

To achieve frequency-dependent characteristic impedance $\left(Z_{0}{ }^{\prime}(\omega)\right)$, the frequency-dependent capacitance $(C(\omega))$ of Eqn. (9) is replaced into the capacitance $(C)$ in Eqn. (13). Therefore, frequency-dependent characteristic impedance is [6]

$$
Z_{0}^{\prime}(\omega)=\sqrt{\frac{L}{C[A(\omega)-j B(\omega)]}}=\frac{Z_{0}}{\sqrt{A(\omega)-j B(\omega)}}
$$

Now, the frequency-dependent (lossy) Smith-chart can be derived through input of $Z_{0}^{\prime}(\omega$ in Eqn. (14) into the normalized terminal impedance expression as done in traditional Smith-chart model. Therefore the normalized terminal impedance $Z_{L}^{\prime}$ is

$$
Z_{L}^{\prime}=\frac{Z_{L}}{Z_{0}^{\prime}(\omega)}=b r+j b x \quad \text { (Dimensionless) }
$$

As $r$ and $x$ are the normalized resistance and normalized reactance, and $b=\sqrt{A(\omega)-j b(\omega)}$.

The voltage reflection coefficient of present Smith chart is

$$
\Gamma^{\prime}=\Gamma_{r}^{\prime}+j \Gamma_{i}^{\prime}=\frac{Z_{L}^{\prime}-1}{Z_{L}^{\prime}+1}
$$

Or

$$
Z_{L}^{\prime}=\frac{Z_{L}}{Z_{0}^{\prime}(\omega)}=b r+j b x=\frac{\left(1+\Gamma_{r}^{\prime}\right)+j \Gamma_{i}^{\prime}}{\left(1-\Gamma_{r}^{\prime}\right)-j \Gamma_{i}^{\prime}}
$$

Microstrip patch antenna can be fed by either two methods, contacting and non-contacting [9]. For contacting method, the RF power is fed directly to the radiating patch using microstrip line as a connecting element. Whereas non-contacting method, electromagnetic field coupling is conducted to transfer power from microstrip line to radiating patch. There are four most commonly used techniques which are microstrip line, coaxial probe (both contacting schemes), aperture coupling and proximity coupling (both non-contacting schemes).

In this research microstrip line feed technique is adopted for the proposed antenna as shown in Fig. 2. The technique used is such that the conducting strip is connected to the edge of the microstrip patch. "The conducting strip is smaller in width as compared to the patch. This kind of feed arrangement has the advantage that the feed can be etched on the same substrate to provide a planar structure"[10].

An inset cut can be incorporated into the patch in order to obtain good impedance matching without the need for any additional matching element. This is successful if the inset position is properly controlled. It provides ease of fabrication and simplicity in modeling as well as impedance matching. "However as the thickness of the dielectric substrate increases, surface waves and spurious feed radiation also increases, which hampers the bandwidth of the antenna"[10]. This type of feeding technique results in undesirable cross 
polarization effects.

The gap between the ground plane and the patch is called the feed gap denoted as ' $g$ ', which is a critical parameter for controlling antenna performance. The microstrip patch antenna dimensions are calculated: width of the patch $\left(W_{p}\right)$, Length of the patch $\left(L_{p}\right)$, width of the substrate $\left(W_{s}\right)$, Length of the substrate $\left(L_{s}\right)$. It is observed that as value of $\mathrm{g}$ increases the antenna impedance, bandwidth (BW) and antenna radiation efficiency $(\eta)$ also increases.

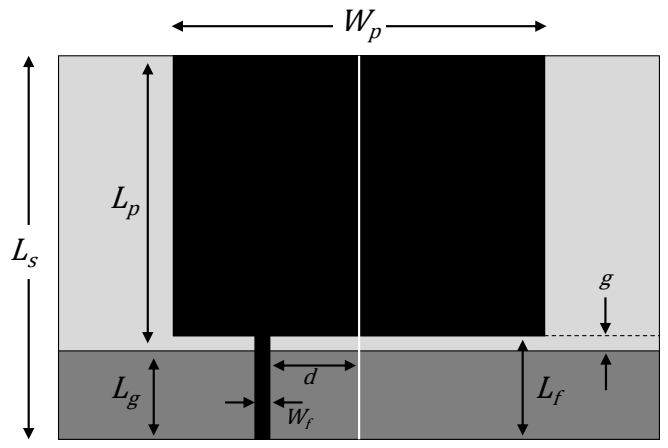

Fig. 2. Geometry of microstrip patch antenna.

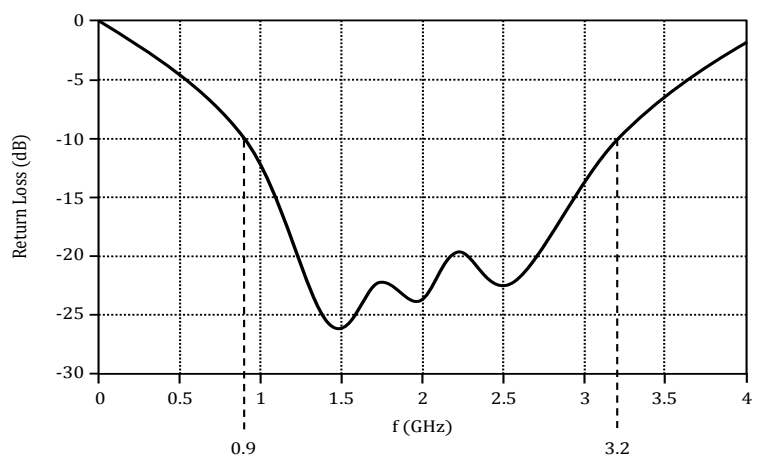

Fig. 3. Return loss at $g=5 \mathrm{~mm}$

TABLE I: DIMENSIONS OF PROPOSED ANTENNA

\begin{tabular}{cc}
\hline \hline Parameter & Value $(\mathrm{mm})$ \\
\hline$L_{p}$ & 67.55 \\
$W_{p}$ & 62.15 \\
$L_{s}$ & 84.35 \\
$W_{s}$ & 99.53 \\
$L_{g}$ & 29.54 \\
$L_{f}$ & 25.55 \\
$W_{f}$ & 2.35 \\
$d$ & 15.25 \\
\hline \hline
\end{tabular}

\section{RESULTS AND DISCUSSIONS}

In this paper, a rectangular patch antenna dimensions are optimized using an in-house MATLAB program by using the asymmetrical feed and a reduction in ground plane with proper gap distance technique from the reference [11]. The proposed antenna is printed on a FR-4 substrate with the thickness $h=1.6 \mathrm{~mm}$ and permittivity $\varepsilon_{r}=4.4$ and fed by a $50 \Omega$ microstrip line which is located at a distance $g$ from the central axis for better impedance matching.

The shape of the patch, position and width of feed line and ground plane dimensions are obtained to achieve $10 \mathrm{~dB}$ impedance bandwidth. The dimensions of the proposed antenna are listed in Table I.

Indicated in Fig. 3, the bandwidth obtained for optimum value at $g=5 \mathrm{~mm}$ is $2.3 \mathrm{GHz}$ (frequency range: $0.9 \mathrm{GHz}$ $3.2 \mathrm{GHz})$.

\section{CONCLUSION}

A simple design method of broadband rectangular microstrip antenna is introduced. In this paper, we propose a procedure to design a broadband rectangular patch antenna by using asymmetrical feed and a reduction in ground plane with proper gap distance to improve the bandwidth. The antenna in this research can be used in various broadband applications. The method proposed in this paper is fully compatible with computer-aided microstrip design.

\section{REFERENCES}

[1] M. Ali, A. Kachouri, and M. Samet, "Compact dual-band microstrip antenna for universal 2.4 /5.2GHz WLAN applications," in Proc. 2011 International Conference on Communications, Computing and Control Applications (CCCA), 2011, pp. 1-4.

[2] P. Agrawal, S. Sanal, G. Gulati, and A. Kumar, "Comparative Study of Feeding Mechanism Used in Microstrip Patch Antenna System," International Association of Scientific Innovation and Research (IASIR), vol. IJETCAS 13-170, pp. 377-382, 2013.

[3] R. Garg, Microstrip Antenna Design Handbook, Artech House, 2001.

[4] A. S. Chavan, P. N. Shah, and S. Mishra, "Analysis of dual frequency microstrip antenna using shorting wall," International Journal of Emerging Technology and Advanced Engineering, vol. 3, 2013.

[5] T. Huque, A. A. Chowdhury, K. Hosain, and S. Alam, "Performance analysis of corporate feed rectangular patch element and circular patch element 4x2 microstrip array antennas," International Journal of Advanced Computer Science and Applications, vol. 2, 2011.

[6] S. Malisuwan and M. Charoenwattanaporn, "Modified smith-chart representation as applied to microstrip antenna design for wireless LAN applications," in Proc. 2003 IEEE International Symposium on Electromagnetic Compatibility, 2003, pp. 150-153, vol.1.

[7] F. Abboud, J. P. Damiano, and A. Papiernik, "Simple model for the input impedance of coax-fed rectangular microstrip patch antenna for CAD," Microwaves, Antennas and Propagation, IEE Proceedings $H$, vol. 135, pp. 323-326, 1988.

[8] P. Berini and L. Roy, "Conductors, electric," in Wiley Encyclopedia of Electrical and Electronics Engineering, ed: John Wiley \& Sons, Inc., 2001.

[9] E. Lopelli, J. Tang, and A. Roermund, "A one-way link transceiver design," in Architectures and Synthesizers for Ultra-low Power Fast Frequency-Hopping WSN Radios, ed: Springer Netherlands, 2011, pp. 93-166.

[10] S. Singh, N. Agarwal, N. Nitin, and A. Jaiswal, "Design consideration of microstrip patch antenna," International Journal of Electronics and Computer Science Engineering, vol. 2, pp. 306-316, 2012.

[11] L. Koyya, R. L. Valluri, and G. Raju, "Optimization of geometry of microstrip patch antenna for broadband applications," International Journal of Advanced Research in Electrical, Electronics and Instrumentation Engineering, vol. 2, 2013.

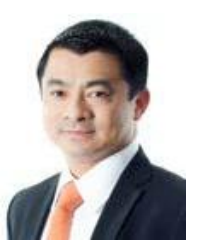

Settapong Malisuwan was born on 24 March 1966 in Bangkok, Thailand. He received his $\mathrm{PhD}$ in electrical engineering (telecommunications), specializing in EMI/EMC from Florida Atlantic University (State University System of Florida), Boca Raton in 2000. He received an $\mathrm{MSc}$ in electrical engineering in mobile communications system, from George Washington University in 1996, an MSc in electrical engineering from Georgia Institute of Technology in 1992 and a BSc in electrical engineering from the Chulachomklao Royal Military Academy, Nakhon-Nayok, Thailand in 1990. He served in the Royal Thai ArmedForces for more than 25 years. His research interests are in efficient spectrum management and telecommunications policy and management. Col. Dr. Settapong Malisuwan is currently the elected vice chairman and a board member in the National Broadcasting and Telecommunications Commission, Thailand. 


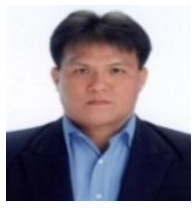

Jesada Sivaraks was born on 12 May, 1970 in Bangkok, Thailand. He received his MSEE degree from Oklahoma State University in 1996 and He received his BEng from King Mongkut"s Institute of Technology, Thailand. He completed his $\mathrm{PhD}$ in electrical engineering at Florida Atlantic University, Boca Raton, FL in 2001. Since 2011, he has been working in National Broadcasting and Telecommunications Commission as the secretary to the vice chairman. His PhD work is on the system aspects of Bluetooth, WLAN and Mobile IP/CDPD. His current research interests are in telecommunication planning and related system analysis and efficient spectrum management. He is a member of Tau Beta Pi, Florida Epsilon and was an Honorary Advisory's Chairman of Science \& Technology committee of Parliament in 2009.

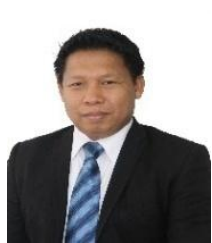

Noppadol Tiamnara was born on 12 November, 1968 in Pah Na Korn Sri Ayuttaya, Thailand. He received his degree diploma of vocational education in Industrial Technology from South-East Asia Colledge, Thailand, 1990, and He received his bachelor degree of electrical engineering from Saint John's University, Thailand, 2002. He received the master degree of master of science (technology management) from Thammasart University, Thailand, 2012. Since 2006, he has been working in
National Broadcasting and Telecommunications Commission as assistant of vice chairman of National Broadcasting and Telecommunication Commission (NBTC). His research interests include LTE design, wireless systems, microstrip antenna and applied electromagnetic.

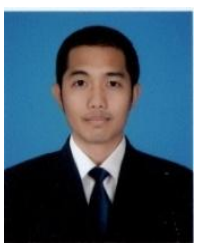

Nattakit Suriyakrai was born in Khonkhaen, Thailand on 22 March, 1987. He received his bachelor of libera arts in Japanese Language from Thammasat University in 2010. He has been working as an assistant to vice chairman in National Broadcasting and Telecommunications, Bangkok, Thailand since November 2012. His research interests are in technology management and spectrum management. 